\title{
AN AERIAL RADIOLOGICAL SURVEY OF THE DAVIS-MONTHAN AIR FORCE BASE AND SURROUNDING AREA
}

TUCSON, ARIZONA 


\section{DISCLAIMER}

This report was prepared as an account of work sponsored by an agency of the United States Government. Neither the United States Government nor any agency thereof, nor any of their employees, makes any warranty, express or implied, or assumes any legal liability or responsibility for the accuracy, completeness, or usefulness of any information, apparatus, product, or process disclosed, or represents that its use would not infringe privately owned rights. Reference herein to any specific commercial product, process, or service by trade name, trademark, manufacturer, or otherwise, does not necessarily constitute or imply its endorsement, recommendation, or favoring by the United States Government or any agency thereof. The views and opinions of authors expressed herein do not necessarily state or reflect those of the United States Government or any agency thereof.

This report has been reproduced directly from the best available copy.

Available to DOE and DOE contractors from the Office of Scientific and Technical Information, P.O. Box 62, Oak Ridge, Tennessee 37831; prices available from (615) 576-8401.

Available to the public from the National Technical Information Service, U.S. Department of Commerce, 5285 Port Royal, Springfield, Virginia 22161. 


\section{DISCLAIMER}

Portions of this document may be illegible electronic image products. Images are produced from the best available original document. 


\title{
AN AERIAL RADIOLOGICAL SURVEY OF THE DAVIS-MONTHAN AIR FORCE BASE AND SURROUNDING AREA
}

\author{
TUCSON, ARIZONA
}

DATE OF SURVEY: MARCH 1-13, 1995

D. P. Colton

Project Scientist

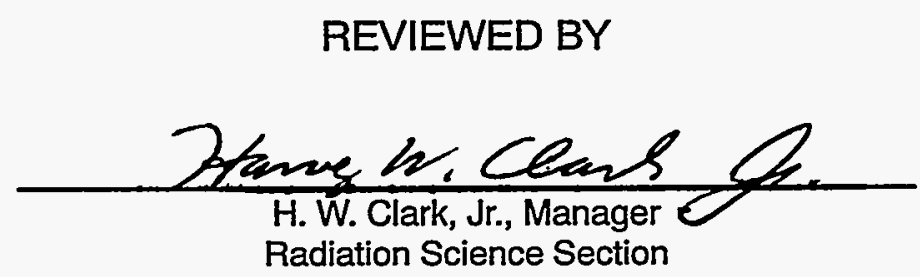

Radiation Science Section

This Document is UNCLASSIFIED

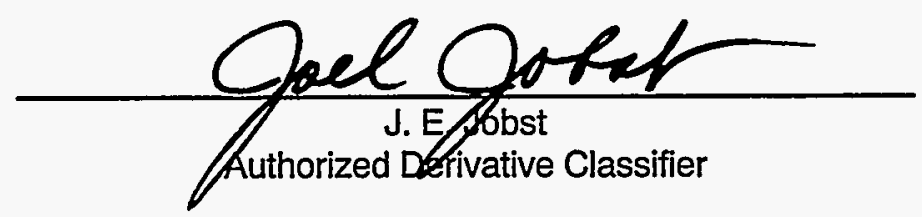

This work was performed by EG\&G/EM for the United States Department of Energy and the United States Department of Defense under Contract Number DE-AC08-93NV11265. 


\begin{abstract}
An aerial radiological survey, which was conducted from March 1 to 13,1995 , covered a 51 -square-mile (132-square-kilometer) area centered on the Davis-Monthan Air Force Base (DMAFB) in Tucson, Arizona. The results of the survey are reported as contours of bismuth-214 $\left({ }^{214} \mathrm{Bi}\right)$ soil concentrations, which are characteristic of natural uranium and its progeny, and as contours of the total terrestrial exposure rates extrapolated to one meter above ground level. All data were scaled and overlaid on an aerial photograph of the DMAFB area. The terrestrial exposure rates varied from 9 to 20 microroentgens per hour at one meter above the ground. Elevated levels of terrestrial radiation due to increased concentrations of ${ }^{214} \mathrm{Bi}$ (natural uranium) were observed over the Southern Pacific railroad yard and along portions of the railroad track bed areas residing both within and outside the base boundaries. No man-made, gamma ray-emitting radioactive material was observed by the aerial survey.

High-purity germainium spectrometer and pressurized ionization chamber measurements at eight locations within the base boundaries were used to verify the integrity of the aerial results. The results of the aerial and groundbased measurements were found to be in agreement. However, the ground-based measurements were able to detect minute quantities of cesium-137 (137 Cs) at six of the eight locations examined. The presence of ${ }^{137} \mathrm{Cs}$ is a remnant of fallout from foreign and domestic atmospheric nuclear weapons testing that occurred in the 1950 s and early 1960s. Cesium-137 concentrations varied from 0.1 to 0.3 picocuries per gram, which is below the minimum detectable activity of the aerial system.
\end{abstract}




\section{CONTENTS}

Abstract

\section{Sections}

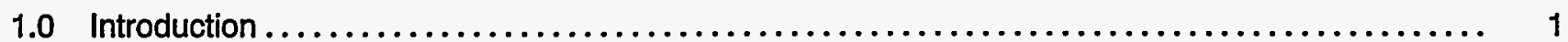

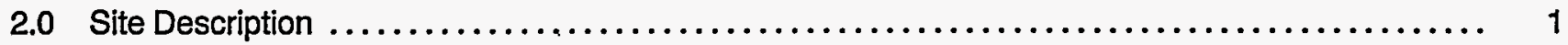

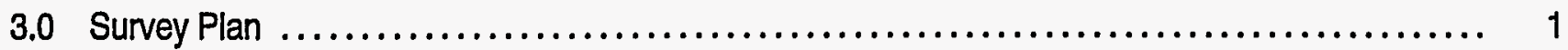

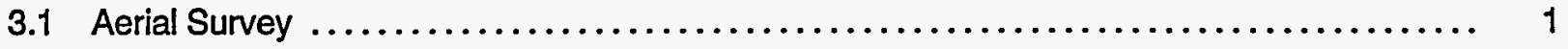

3.2 Ground-Based Measurements $\ldots \ldots \ldots \ldots \ldots \ldots \ldots \ldots \ldots \ldots \ldots \ldots \ldots \ldots \ldots \ldots \ldots \ldots$

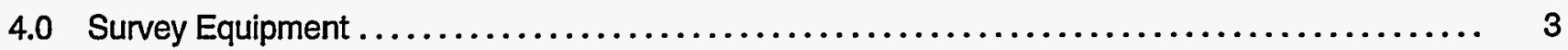

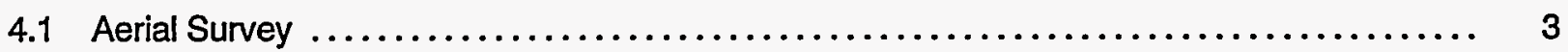

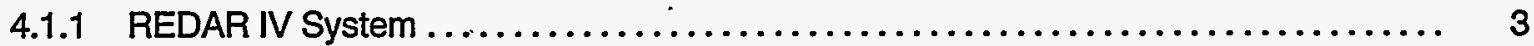

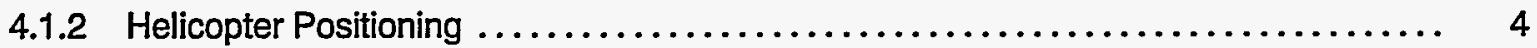

4.1.3 Data Processing ........................................ 4

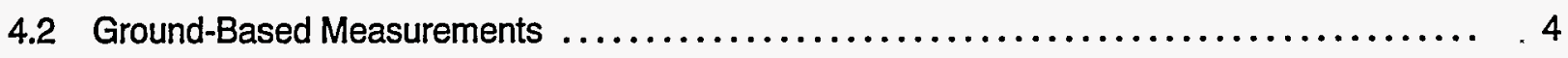

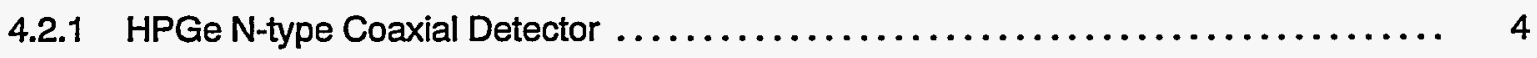

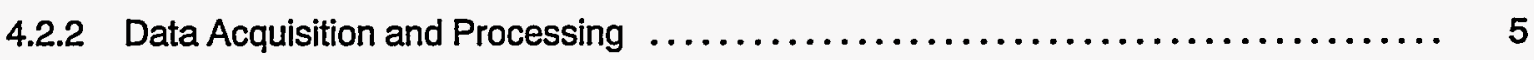

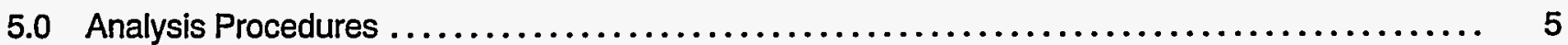

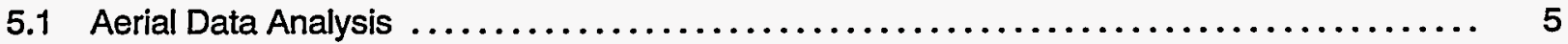

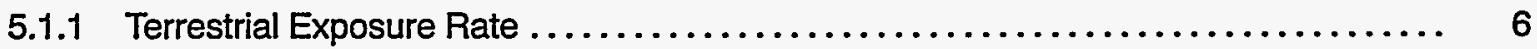

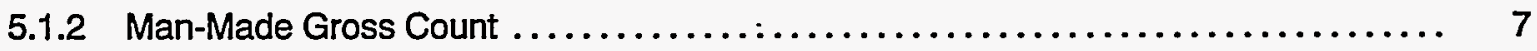

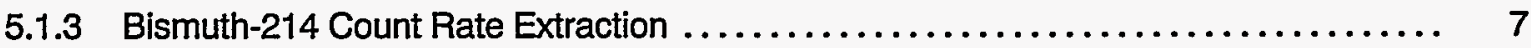

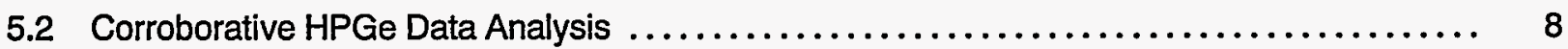

5.3 Conversion Factors $\ldots \ldots \ldots \ldots \ldots \ldots \ldots \ldots \ldots \ldots \ldots \ldots \ldots \ldots \ldots \ldots \ldots \ldots \ldots \ldots$

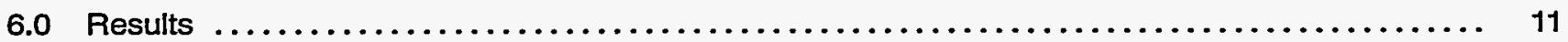

6.1 Terrestrial Gamma Exposure Rate Contour $\ldots \ldots \ldots \ldots \ldots \ldots \ldots \ldots \ldots \ldots \ldots \ldots \ldots \ldots \ldots$

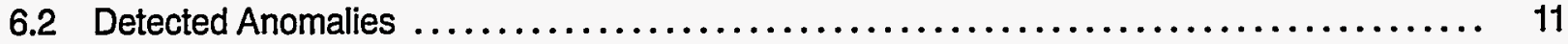

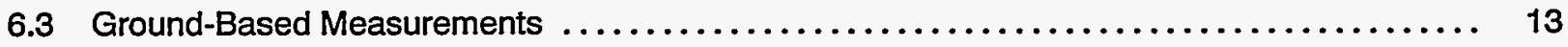

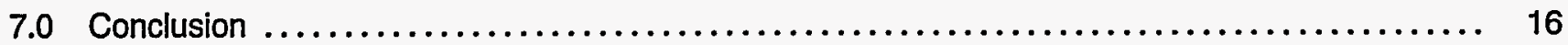

\section{Figures}

1 DMAFB Survey Area Boundaries and Flight Pattern 


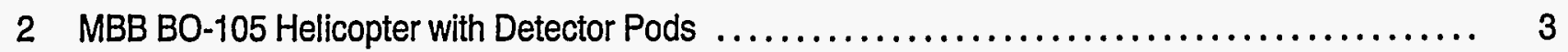

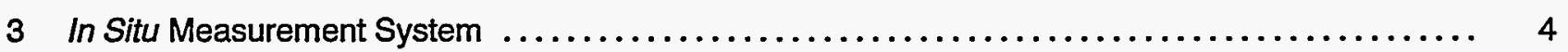

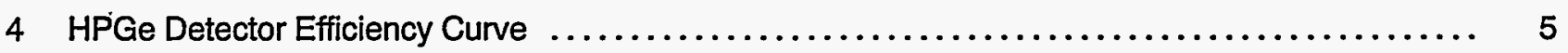

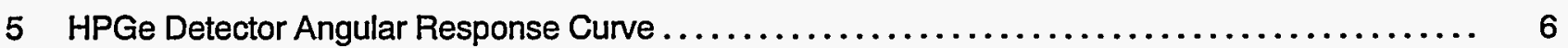

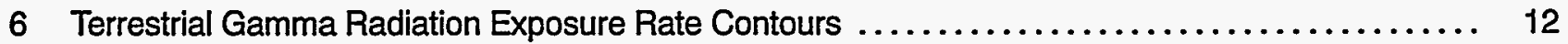

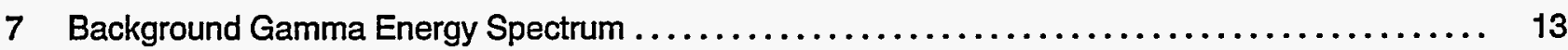

8 Net Gamma Energy Spectrum of the Enhanced Natural ${ }^{214}$ Bi Activity
over the Southern Pacific Railroad Yard $\ldots \ldots \ldots \ldots \ldots \ldots \ldots \ldots \ldots \ldots \ldots \ldots \ldots \ldots \ldots \ldots \ldots \ldots \ldots$

9 Isoradiation Contours Showing Enhanced Natural ${ }^{214}$ Bi Activity ....................... 14

10 HPGe Gamma Energy Spectrum of the DMAFB Rifle Range Area (Site 7) $\ldots \ldots \ldots \ldots \ldots \ldots \ldots \ldots$

\section{Tables}

1 DMAFB Survey Minimum Detectable Activities $\ldots \ldots \ldots \ldots \ldots \ldots \ldots \ldots \ldots \ldots \ldots \ldots \ldots \ldots \ldots \ldots \ldots, \quad 3$

2 DMAFB Survey Conversion Factors $\ldots \ldots \ldots \ldots \ldots \ldots \ldots \ldots \ldots \ldots \ldots \ldots \ldots \ldots \ldots \ldots \ldots \ldots \ldots \ldots \ldots, \quad 8$

3 Comparison of Aerial and Ground-Based Measurements $\ldots \ldots \ldots \ldots \ldots \ldots \ldots \ldots \ldots \ldots \ldots, \quad 9$

4 In Situ Meașurements Soil Concentration Results ................................ 15

\section{Appendices}

A Survey Parameters $\ldots \ldots \ldots \ldots \ldots \ldots \ldots \ldots \ldots \ldots \ldots \ldots \ldots \ldots \ldots \ldots \ldots \ldots \ldots \ldots \ldots \ldots \ldots, 17$

B In Situ Measurement Parameters .......................................... 18

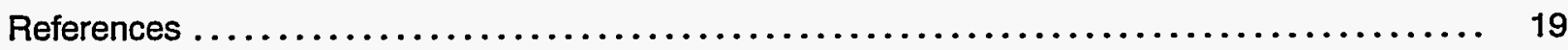




\subsection{INTRODUCTION}

An aerial radiological survey of the Davis-Monthan Air Force Base (DMAFB) in Tucson, Arizona, was conducted from March 1 to 13,1995, at the request of the United States Department of Defense (DoD). The survey, covering a 51-square-mile (132-square-kilometer) area centered on the DMAFB, was conducted by the United States Department of Energy's (DOE) Remote Sensing Laboratory (RSL), which is maintained and operated for DOE by EG\&G Energy Measurements, Inc. (EG\&G/EM) in Las Vegas, Nevada.

The purpose of the survey was to measure and map the natural and man-made gamma radiation emanating from the area within and surrounding the base boundaries. This survey was the first of its type at DMAFB and was conducted as a routine part of, and in conjunction with, an on-going DoD base restoration and waste management study that was started in September 1994. ${ }^{1}$

High-purity germanium (HPGe) spectrometer and pressurized ionization chamber measurements, collected at a height of one meter above the ground level (AGL) at eight locations within the base boundaries, were used to verify the integrity of the aerial radiological and exposure rate results.

\subsection{SITE DESCRIPTION}

DMAFB, a key installation of the Air Combat Command, is located adjacent to and south of Tucson, Arizona. The base encompasses a fenced area of approximately 10,000 acres with an average elevation of 2,700 feet ( 823 meters) above sea level. The base supports primarily activities from the 305th and 355th Wing Commands. Aircraft routinely flown from the base include the $A-10$, the $O A-10$, and the EC-103H.

The base is also the home of the Aerospace Maintenance and Regeneration Center (AMARC), which is an agency under the Air Force Material Command. AMARC is a major industrial center that provides for the storage, regeneration, reclamation, and disposal of aircraft and aerospace items that are no longer needed by the DoD. AMARC encompasses an area of 2,600 acres and has more than 4,700 aircraft in storage. 2

Past operations at the DMAFB have involved the transport, storage, and use of nuclear materials, aircraft decontamination, and the removal and disposal of aircraft radioactive instrumentation and components (instrument gauges with radium-painted dials, depleted uranium counterweights, etc). ${ }^{1}$

The area surrounding the DMAFB is primarily comprised of the population and industrial centers of southern Tucson. Also, the Tucson International Airport resides approximately 5 miles $(8 \mathrm{~km})$ to the southwest. The survey area included a coal-burning electric power generation plant, the Southern Pacific railroad yard, and some forest and farm land.

\subsection{SURVEY PLAN}

\subsection{Aerial Survey}

The aerial survey was conducted to collect gamma radiation data over a $51-\mathrm{mi}^{2}\left(132-\mathrm{km}^{2}\right)$ area encompassing the DMAFB and surrounding area. The boundary was initially selected to enclose the entire base with a $0.5-1.0-\mathrm{mi}(0.8-1.6-\mathrm{km})$ area overlap. In addition, the boundary was extended in the northwest to include the Southern Pacific railroad yard and the Detention Basin.

The area was surveyed by flying at a constant ground speed of 70 knots ( 36 meters per second), at a nominal altitude of 150 feet (46 meters) above ground level along a set of parallel flight lines spaced 250 feet (76 meters) apart, which total 1,070 flight line miles (1,720 kilometers). To minimize interference with DMAFB air traffic, the flight lines were oriented parallel to the DMAFB active runway and were flown in either a southeasterly or northwesterly direction, Figure 1. All data were scaled to overlay an aerial photograph (dated March 1995) of the DMAFB area. In order to assure data integrity and to monitor/correct for variations in the detector's background radiation due to aircraft, radon, and cosmic rays, measurements were made over a fixed test line before and after each flight. The fixed test line (TL) was located along a dirt road that was approximately 1,000 feet $(305 \mathrm{~m})$ to the south and parallel with the DMAFB active runway. For the survey parameters cited, the minimum detectable activities (MDAs) for the isotopes of interest are shown in Table 1. The isotopes of interest are: 1) bismuth-214 $\left({ }^{214} \mathrm{Bi}\right)$, which is characteristic of natural uranium and its progeny; 2) cesium-137 ( $\left.{ }^{137} \mathrm{Cs}\right)$, which is representative of the worldwide fallout attributed to the various atmospheric nuclear weapons testing programs; and 3) protactinium-234m ( $234 \mathrm{mPa})$, which is characteristic of depleted uranium (DU) and is associated with the composition of aircraft counterweight components. 


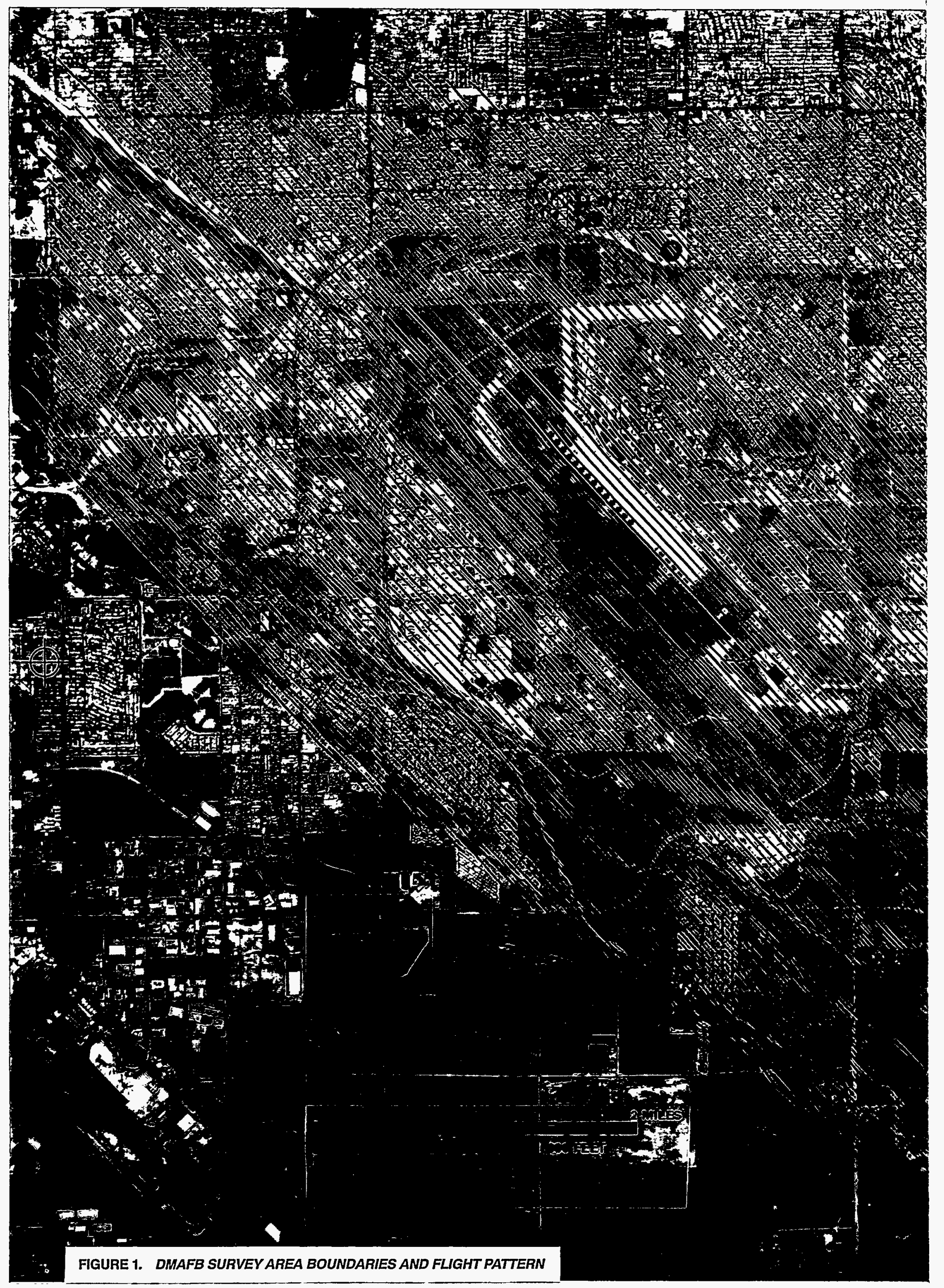




\subsection{Ground-Based Measurements}

During the DMAFB survey, a set of corroborative ground-based measurements were performed at eight locations within the base boundaries. These measurements were used to verify the integrity of the aerial data and to detail the radionuclide content of the natural background radiation on the base. The locations selected were not near any obvious radiation anomalies and were areas readily accessible to the general onsite personnel. Each set of ground-based measurements consisted of a total gamma energy spectral (in situ) measurement and a total terrestrial gamma exposure rate measurement, both of which were collected at a height of one meter above the ground. For the in situ measurements, each was made for a live-time collection interval of 900 seconds (15 minutes). As a quality control check and to monitor/correct for variations in the detector's background radiation, measurements were made at a fixed control point prior to and after each day's measurements. The fixed control point (CP) was located on DMAFB in a grass field directly behind the Building 1750 parking lot. For the isotopes of interest, the MDAs for the in situ measurements are shown in Table 1.

\subsection{SURVEY EQUIPMENT}

\subsection{Aerial Survey}

The survey was conducted using RSL's Aerial Measuring System (AMS), which consists of a Messerschmitt-Bolkow-Blohm (MBB) BO-105 helicopter, a Radiation and Environmental Data Acquisition and Recorder Version IV (REDAR IV) system, and a Realtime Differential Global Positioning System (RDGPS), Figure 2.

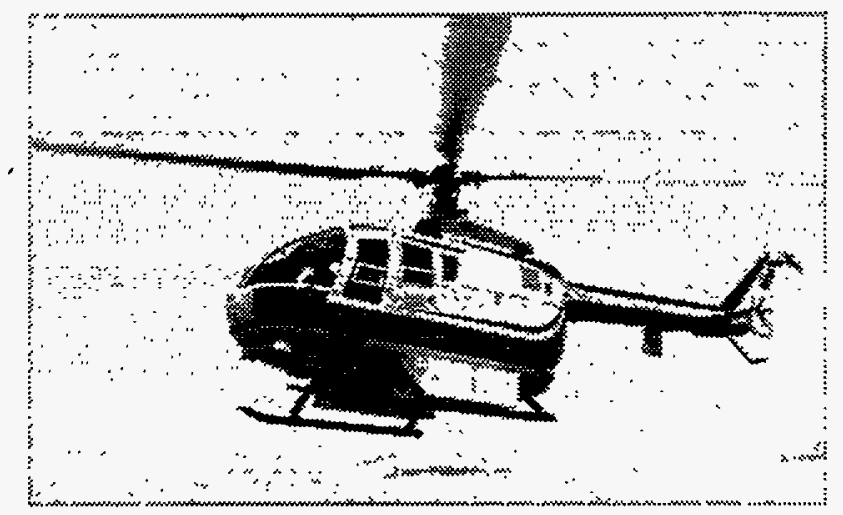

FIGURE2 MBB B0-105 HELICOPTER WITH DETECTOR PODS

The helicopter was equipped with two large detector pods that were mounted on the side of the helicopter's landing skids. Each pod contained four $4-\times 4-. \times$ 16-inch and one 2- $\times 4-\times 4$-inch thallium-activated sodium-iodide, $\mathrm{Nal}(\mathrm{T} l)$, gamma ray detectors. Normally, the detector pods are equipped with the 2- $X$ 4- $\times 16$-inch logs. However, the desire to accurately measure the 1,764-keV gamma rays from ${ }^{214} \mathrm{Bi}$ necessitated the use of the thicker detector. The preamplifier signal from each detector was calibrated using sodium-22 $\left({ }^{22} \mathrm{Na}\right)$ and americium-241 $\left({ }^{241} \mathrm{Am}\right)$ gamma check sources. Normalized outputs from each detector were combined in an eight-way summing amplifier and the signal was adjusted in the analog-to-digital converter so that the calibration photopeaks appeared in preselected channels in the REDAR IV multichannel analyzer.

\subsubsection{REDAR IV System}

Data acquisition was performed using the REDARIV system, a multimicroprocessor, portable data acquisition and real-time analysis system designed for use in aircraft. The REDAR IV collects 1,024 channels (4

\begin{tabular}{|l|c|c|c|c|c|}
\hline \multicolumn{5}{|c|}{ Table 1. DMAFB Survey Minimum Detectable Activities } \\
\hline \multirow{2}{*}{ Isotope } & $\begin{array}{c}\text { Photopeak } \\
\text { (keV) }\end{array}$ & \multicolumn{2}{|c|}{ Aerial Surveya } & \multicolumn{2}{c|}{ In Situ Measurements ${ }^{\mathbf{b}}$} \\
\cline { 3 - 6 } & $\mu \mathrm{Ci} / \mathrm{m}^{2}$ & $\mathrm{pCi} / \mathrm{g}$ & $\mu \mathrm{Ci} / \mathrm{m}^{2}$ & $\mathrm{pCi} / \mathrm{g}$ \\
\hline${ }^{214} \mathrm{Bi}$ & 1,765 & 0.25 & 1.2 & 0.04 & 0.17 \\
${ }^{137} \mathrm{Cs}$ & 662 & 0.05 & 0.3 & 0.02 & 0.10 \\
$234 \mathrm{mPa}$ & 1,001 & 10.0 & 53.5 & 1.2 & 6.7 \\
\hline
\end{tabular}

a Derived for ground speed of $36 \mathrm{~m} / \mathrm{s}$, nominal altitude of $46 \mathrm{~m}$, and line spacing of $76 \mathrm{~m}$.

bDerived for soil sample depth (z) of $3 \mathrm{~cm}$ and inverse relaxation depth $(\alpha)$ of $0.1 \mathrm{~cm}^{-1}$, except for ${ }^{214} \mathrm{Bi}$ where $\alpha$ equals $1.0 \mathrm{E}-06 \mathrm{~cm}^{-1}$. 
$\mathrm{keV} / \mathrm{channel)}$ of gamma energy spectral data once every second and then records the spectral data, the aircraft altimeter and positioning data, and the environmental variables such as ambient temperature and barometric pressure to magnetic tape cartridges once every four seconds. The REDAR IV is also equipped with multichannel analyzer and CRT display capabilities for in-flight monitoring of the gamma energy spectral data as well as other flight parameters. The detector and electronic system are described in detail in a separate publication. ${ }^{3}$

\subsubsection{Helicopter Positioning}

The helicopter's position was established by using two systems: the RDGPS and a radar altimeter. The RDGPS is a navigation system providing continuous position information accurate to \pm 16 feet ( 5 meters) using a constellation of 24 satellites. The radar aitimeter determines the helicopter's altitude by measuring the round-trip propagation time of a signal reflected off the ground.

\subsubsection{Data Processing}

At the end of each flight, the aerial data were downloaded for processing from the magnetic tape cartridges into the Radiation and Environmental Data Analysis Computer (REDAC) system. The REDAC was housed in a modified Airstream mobile home which was parked at the 305th Rescue Squadron hangar, DMAFB Building 1750. The REDAC system utilizes: (1) a computer with 8-megabytes of memory for data manipulation, (2) two gigabytes of hard disk space for mass storage of data, (3) two 1/4-inch digital magnetic tape cartridge drives for reading the REDAR data tapes, (4) one Exabyte tape drive for data transfer and archiving, (5) a 36-inch-wide graphics plotter for data contouring, and (6) two video graphics display stations. The system uses an extensive library of software which provides onsite preliminary analysis of the aerial data on a flight-by-flight basis and monitors preand post-flight quality assurance checks. $A$ similar REDAC system was used to complete the data analysis process at RSL in Las Vegas, Nevada.

\subsection{Ground-Based Measurements}

The ground-based measurements were conducted using a Reuter-Stokes pressurized ionization chamber and RSL's in situ gamma acquisition and analysis system, which consists of an ORTEC high-purity germanium (HPGe), N-type, coaxial detector; a Davidson multichannel, pulse-height analyzer (MCA); a one-meter-high tripod; and an external $12 \mathrm{~V}$ Gel-cell battery pack. Both sets of measurements were acquired at a height of one meter AGL. Postprocessing of the gamma energy spectral data was performed on a portable GRID laptop computer.

\subsubsection{HPGe N-type Coaxial Detector}

One ORTEC HPGe, N-type, coaxial detector was used to collect the gamma energy spectral data. The detector was mounted on a tripod with the face of the detector suspended one meter above the ground. Figure 3 shows a typical setup for the field measurements.

The detector was equipped with an ultra-thin $(0.8 \mathrm{~mm})$ beryllium endcap window and a 1.2-liter liquid nitrogen dewar. The detector element was $72 \mathrm{~mm}$ in diameter with a length of $85 \mathrm{~mm}$. Prior to leaving RSL, the detector was calibrated for efficiency and angular response. Figures 4 and 5 show the calibration

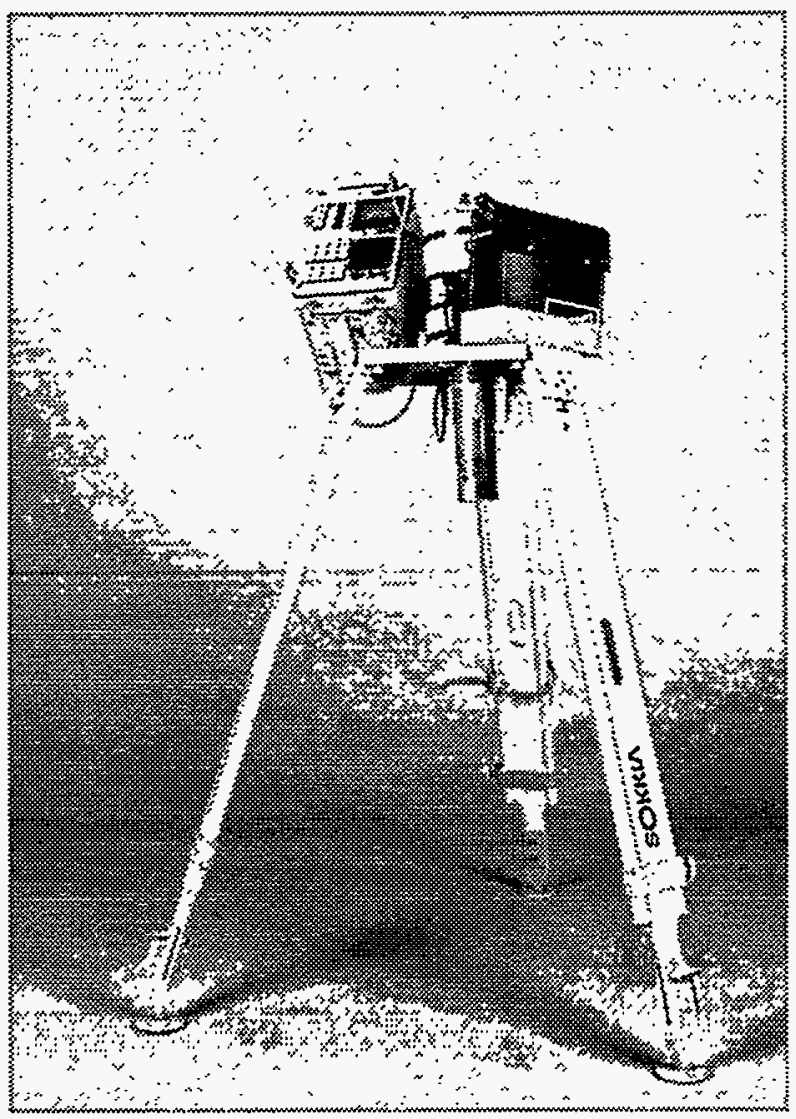

FIGURE 3. IN SITU MEASUREMENT SYSTEM 


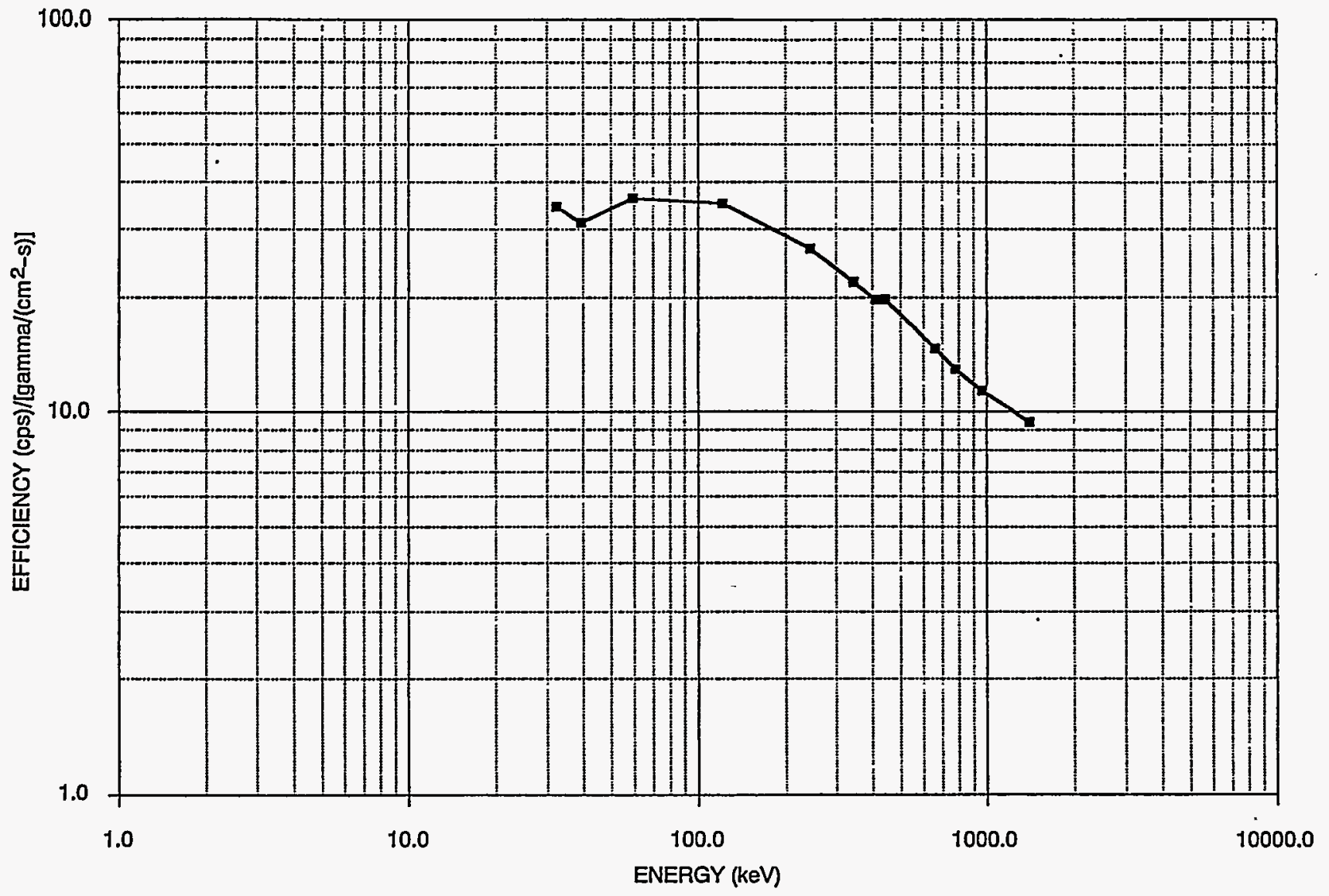

FIGURE 4. HPGe DETECTOR EFFICIENCY CURVE

results. Individual soil concentration conversion factors were developed using these calibration data.

\subsubsection{Data Acquisition and Processing}

The output signal from the HPGe detector was fed via coaxial cable to a battery-operated, 4,096-channel, portable analyzer (MCA). The system was set to a fullscale energy of $3,000 \mathrm{keV}$. An energy calibration check was made each morning during the initial equipment setup while at the fixed base, as well as prior to starting the measurements in the field.

The MCA has the capability to acquire, display, and perform preliminary data analysis on the acquired gamma energy spectra. The acquired spectral data were stored on mini data cassettes for later retrieval. Also, the MCA has the ability to transfer the data digitally via an EIA RS-232C serial port to a GRID laptop computer, where the postprocessing of the data was performed.
The positions of the in situ measurement locations were established using an autonomous Global Positioning System hand-held monitor. The monitor provided position information to an accuracy of $\pm 100-500 \mathrm{ft}(30-150 \mathrm{~m})$, dependent upon the military selective availability at the time of the measurement.

\subsection{ANALYSIS PROCEDURES}

\subsection{Aerial Data Analysis}

The aerial radiation data generally consist of contributions from naturally-occurring radionuclides, manmade radionuclides, airbome radon, cosmic rays, and aircraft-induced electronic noise. For this survey, the major emphasis was placed on mapping the gamma radiation environment of the DMAFB and surrounding area. Isopleth maps were produced by processing the aerial data using the extraction methods discussed in this section. More detailed information can be found in a separate publication. ${ }^{3}$ 


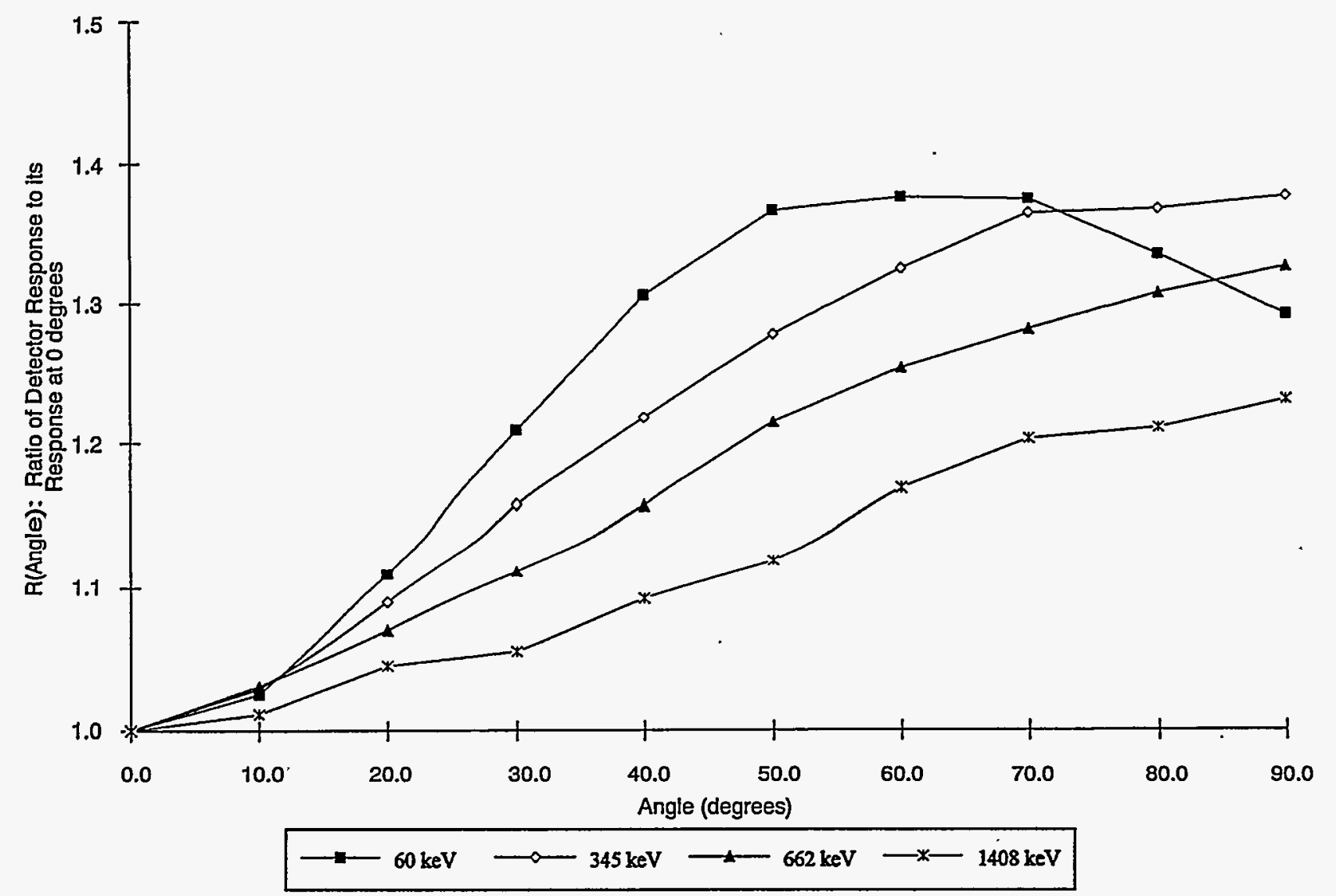

FIGURE 5. HPGE DETECTOR ANGULAR RESPONSE CURVE

\subsubsection{Terrestrial Exposure Rate}

The terrestrial exposure rate or gross count (GC) method is based on the integral count rate in the gamma energy spectral range between 38 and 3,026 keV:

$$
C R_{G C}=\sum_{E=38}^{3026} S(E)-N T B
$$

where

$$
C R_{G C}=\text { total terrestrial count rate or gross count, }
$$
counts per second (cps)

$$
\begin{aligned}
S(E)= & \text { energy spectrum containing the number of } \\
& \text { gamma rays collected at the given energy } E \\
& \text { per second } \\
E= & \text { the photon energy, keV }
\end{aligned}
$$

$$
\begin{aligned}
N T B= & \text { nonterrestrial background count rate in } \\
& \text { counts per second (cps) produced by the } \\
& \text { effects of airborne radon, cosmic rays, and } \\
& \text { the aircraft-induced electronic noise }
\end{aligned}
$$

The gross count, measured in cps at survey altitude, was converted to an exposure rate in microroentgens per hour $(\mu R / h)$ at a height of one meter above the ground by application of a conversion factor determined from documented calibration test lines in Calvert County, Maryland, and Lake Mohave, Nevada. 4 The conversion equation used is:

$$
E R=\frac{C R_{G C}}{1114} e^{(A-46) \mu_{a i r}}
$$

where

$E R=$ exposure rate extrapolated to one meter AGL, $\mu R / h$ 
$A=$ survey altitude, meters

$$
\mu_{\text {air }}=\text { gamma ray air attenuation coefficient, } \mathrm{m}^{-1}
$$

The air attenuation coefficient, $\mu_{\text {air }}$, deduced empirically from the altitude profile data over the survey's test line, was $0.00576 \mathrm{~m}^{-1}$. The derived conversion factor was $1,114 \mathrm{cps}$ per $\mu \mathrm{R} / \mathrm{h}$ for a survey altitude of $46 \mathrm{~m}$ AGL. The applicability of the conversion equation assumes a uniformly distributed radiation source covering an area which is large when compared to the field of view of the detection system (a circle with a diameter roughly twice the altitude of the aircraft) and has a gamma energy distribution similar to that of the natural background radiation of the Lake Mohave calibration test line.

\subsubsection{Man-Made Gross Count}

The aerial data were also used to determine the location of nonnaturally-occurring gamma sources, i.e., man-made radionuclides. The man-made gross count (MMGC) is the portion of the gross count which is directly attributed to the gamma rays from the manmade radionuclides. In general, evidence of manmade radionuclides can be found from increases in the gross count. However, slight variations in the gross count are generally not considered adequate proof to suspect the presence of a man-made anomaly since these variations can result naturally from geological fluctuations or changes in the ground cover (i.e., rivers, vegetation, buildings, etc.).

In order to increase the sensitivity of the AMS to detect man-made anomalies, a man-made gross count algorithm has been developed that uses differential spectral energy extraction techniques to denote changes in the gamma energy spectral shapes. This algorithm takes advantage of the fact that while background radiation levels often vary by a factor of two or more within a survey area, background spectral shapes remain essentially constant. More specifically, the ratio of natural components in any two sections (windows) of the energy spectrum will remain nearly constant.

Although this procedure can be applied to any region of the gamma energy spectrum, the most common practice is to place all counts below 1,394 keV into the man-made window (low energy sum), where most of the long-lived, man-made radionuclides emit radiation, and to place all counts above 1,394 keV into the natural window (high energy sum), where mostly the naturally-occurring radionuclides emit radiation. The
MMGC rate can be expressed analytically in terms of the integrated count rates in specific gamma energy spectral windows (keV) as

$$
M M G C=\sum_{E=38}^{1394} S(E)-K_{m m} \cdot \sum_{E=1394}^{3026} S(E)
$$

where $K_{m m}$ is defined over an area that only contains gamma radiation from naturally-occurring radionuclides as

$$
K_{m m}=\frac{\sum_{E=38}^{1394} S(E)}{\sum_{E=1394}^{3026} S(E)}
$$

This MMGC algorithm has been found to be sensitive to low levels of man-made radiation even in the presence of large variations in the natural background. Once a region of man-made radioactivity has been identified, a detailed analysis of the gamma energy spectrum is conducted to ascertain which radionuclides are present.

Note that the natural background isotope ${ }^{214} \mathrm{Bi}$ has prominent energy photopeaks at 609 and $1,120 \mathrm{keV}$. Thus, in areas exhibiting excess concentrations of natural ${ }^{214} \mathrm{Bi}$, the overall contribution of the count rates of these two photopeaks in the MMGC source energy window (38-1,394 keV) would be significant, and a "false positive" anomaly may be depicted over those areas on the MMGC contour map.

\subsubsection{Bismuth-214 Count Rate Extraction}

The determination of the contribution to the gross count of an individual isotope requires an algorithm that can identify a specific photopeak's count rate. The simplest of these algorithms is the two-window strip. The two-window stripping method assumes that the photopeak count rate from a specific isotope can be determined from the sum of the counts in the isotope's gamma energy source window minus a scaled background contribution. For the isotope ${ }^{214} \mathrm{Bi}$, which is a progeny of the natural uranium decay chain, the primary photopeak of interest is at $1,765 \mathrm{keV}$. Following the same procedure as outlined in the MMGC section, the ${ }^{214} \mathrm{Bi}$ count rate is given by 


$$
C R_{B i}=\sum_{E=1596}^{1872} S(E)-K_{B i} \cdot \sum_{E=2376}^{2772} S(E)
$$

The constant, $K_{B i}$, is determined over an area that contains only gamma radiation from naturallyoccurring radionuclides and does not contain any excess ${ }^{214} \mathrm{Bi}$. It is defined as

$$
K_{B i}=\frac{\sum_{E=1596}^{1872} S(E)}{\sum_{E=2376}^{2772} S(E)}
$$

Except for the choice of the source and background energy window limits, $C R_{B i}$ is identical in form to $M M G C$, as defined in Equation 3. The background energy limits, 2,376 to 2,772 keV, are chosen in an energy region that contains only naturally-occurring background radiation, namely thallium-208 $\left({ }^{208} \mathrm{TI}\right)$, which is a progeny of the thorium decay chain.

The extracted ${ }^{214} \mathrm{Bi}$ count rates, measured in $\mathrm{cps}$ at survey altitude, were converted to soil concentrations in picocuries per gram ( $\mathrm{pCi} / \mathrm{g}$ ) by application of a conversion factor, Table 2 , which was derived from a radioactive transport matrix model developed by Beck, et al..$^{5}$ This method mathematically models the gamma ray flux through a detector located at some distance above a source distribution. A brief synopsis of this model will be discussed later.

\subsection{Corroborative HPGe Data Analysis}

Initial processing of the HPGe gamma energy spectral data was performed at the DMAFB. Final processing was performed after the team had returned to Las Vegas, Nevada.

In order to maximize sensitivity, each spectrum was individually examined for potential photopeaks from man-made radionuclides. A photopeak window was established for each photopeak of interest. Background windows on either side of the photopeak were used to perform a straight line background subtraction. The net result was then compared to the threesigma value due to the counting statistics in the photopeak and background windows to determine if a peak was present. Although this type of processing is slower than using an automated peak search routine, the method provides more reliability in identifying and properly extracting the net photopeak count rate for weak sources.

Prior to extracting the peak net counts, a three-point, area-preserving, binomial-smoothing algorithm was applied to the spectral data to improve their reliability. The extracted peak net counts were then corrected for system dead time using a nonparalysable counter dead time correction factor and the reported errors, due to a system dead time correction and a one-sigma counting statistics error, were derived. A more detailed explanation of the factors contributing to the derived dead time and standard errors can be found in separate publications.6,7

The net results are reported as soil concentration in $\mathrm{pCi} / \mathrm{g}$ by application of the conversion factors that are listed in Table 2, which were also derived from the works of Beck, et al. 5

\begin{tabular}{|l|c|c|c|c|c|}
\hline \multicolumn{5}{|c|}{ Table 2. } & \multicolumn{2}{c|}{ DMAFB Survey Conversion Factors } \\
\hline \multirow{2}{*}{ Isotope } & \multirow{2}{*}{$\begin{array}{c}\text { Photopeak } \\
(\mathrm{keV})\end{array}$} & \multicolumn{2}{|c|}{ Aerial Survey } & \multicolumn{2}{c|}{ In Situ Measurements } \\
\cline { 3 - 6 } & $\mu \mathrm{Ci} / \mathrm{m}^{2} / \mathrm{cps}$ & $\mathrm{pCi} / \mathrm{g} / \mathrm{cps}$ & $\mu \mathrm{Ci} / \mathrm{m}^{2} / \mathrm{cps}$ & $\mathrm{pCi} / \mathrm{g} / \mathrm{cps}$ \\
\hline${ }^{214} \mathrm{Bi}$ & 1,765 & $8.45 \mathrm{E}-03$ & $3.91 \mathrm{E}-02$ & 0.452 & 1.886 \\
${ }^{137} \mathrm{Cs}$ & 662 & $1.06 \mathrm{E}-03$ & $6.72 \mathrm{E}-03$ & 0.061 & 0.349 \\
${ }^{234 \mathrm{mPa}}$ & 1,001 & $1.67 \mathrm{E}-01$ & $8.91 \mathrm{E}-01$ & 7.0 & 40.0 \\
\hline
\end{tabular}

aDerived for ground speed of $36 \mathrm{~m} / \mathrm{s}$, nominal altitude of $46 \mathrm{~m}$, and line spacing of $76 \mathrm{~m}$.

bDerived for soil sample depth (z) of $3 \mathrm{~cm}$ and inverse relaxation depth $(\alpha)$ of $0.1 \mathrm{~cm}^{-1}$, except for ${ }^{214} \mathrm{Bi}$ where $\alpha$ equals $1.0 \mathrm{E}-06 \mathrm{~cm}^{-1}$. 


\begin{tabular}{|c|c|c|c|}
\hline \multicolumn{3}{|c|}{ Table 3. Comparison of Aerial and Ground-Based Measurements } \\
\hline \multirow{2}{*}{ Site } & \multicolumn{3}{|c|}{ Exposure Rates $(\mu \mathrm{R} / \mathrm{h}$ at 1 meter AGL) } \\
\cline { 2 - 4 } & Ion Chamber & Inferred In Situ ${ }^{\mathrm{b}}$ & Inferred Aerial $^{\mathrm{b}}$ \\
\hline 1 & $13.6(0.3)$ & $12.6(1.0)$ & $14.4(0.3)$ \\
2 & $12.5(0.6)$ & $12.2(0.9)$ & $13.8(0.2)$ \\
3 & $12.8(0.8)$ & $12.0(0.9)$ & $13.6(0.4)$ \\
4 & $12.5(0.4)$ & $12.3(0.9)$ & $14.5(0.1)$ \\
5 & $13.3(0.6)$ & $12.6(0.9)$ & $14.3(0.2)$ \\
6 & $13.6(0.2)$ & $12.6(1.0)$ & $14.8(0.1)$ \\
$7 \cdot$ & $12.2(0.2)$ & $12.3(0.9)$ & $14.7(0.1)$ \\
CP & $12.9(0.8)$ & $12.3(0.9)$ & $13.5(0.4)$ \\
\hline
\end{tabular}

Reported in Table 3 are the inferred in situ exposure rates in $\mu \mathrm{R} / \mathrm{h}$ at one meter above the ground which were computed from the primary isotopic soil concentrations in accordance with the works of Beck, et $a l^{5}$ The inferred in situ exposure rates were derived using the expression

$E R=$ Conc $\cdot \beta \cdot(0.0011655 \cdot$ Energy -0.040$)$

where

$$
\begin{aligned}
E R= & \text { exposure rate at one meter } A G L, \mu R / h \\
C o n c= & \text { isotopic soil concentration given, } \mathrm{pCi} / \mathrm{g} \\
\beta= & \text { decay fraction or branching ratio, } \\
& \gamma / \text { disintegrations } \\
\text { Energy }= & \text { gamma energy, } \mathrm{keV}
\end{aligned}
$$

This expression provides an estimate of the external exposure rate for measured gamma ray energies and is valid for uniformly distributed monoenergetic gamma sources in the soil with energies greater than $100 \mathrm{keV}$. The approximation assumes an error of $8 \%$.

\subsection{Conversion Factors}

Conversion factors have been calculated which relate the measurement photopeak count rate data to the radionuclide activity in the soil. The values are determined by combining a laboratory measurement of the detector efficiency to a given gamma ray energy with a theoretical calculation of the gamma ray flux arriving at the detector as a function of source distribution in the soil.

The unscattered gamma ray flux, $\phi$, from a point source with activity, $S_{o}$, at a distance, $r$, from the source is given by

$$
\phi=\frac{S_{o}}{4 \pi r^{2}} e^{-r / \lambda_{a}}
$$

where $\lambda_{a}$ is the gamma ray mean free path in air. This can also be written as

$$
\phi=\frac{S_{o}}{4 \pi r^{2}} e^{-(\mu / \rho)_{a} p_{a} r}
$$

where

$$
\begin{aligned}
(\mu / \rho)_{a} & =\text { air mass attenuation coefficient, } \mathrm{cm}^{2} / \mathrm{g} \\
\rho_{a} & =\text { air density, } \mathrm{g} / \mathrm{cm}^{3}
\end{aligned}
$$

This expression can be expanded to the more general case of a source distributed within the soil. In this 
case, the unscattered flux of gamma rays of energy, $E$, at a height, $h$, above a smooth air-ground interface due to an emitter distributed in the soil is given by

$$
\phi=\int_{0}^{\infty} \int_{0}^{\infty} \frac{S_{v}}{4 \pi r^{2}} e^{\left[-(\mu / \rho)_{a} \rho_{a} r_{a}\right]_{e}} e^{\left[-\left(\mu / \rho_{s} \rho_{s} r_{s}\right]_{2}\right.} 2 \pi x d x d z
$$

where

$$
\begin{aligned}
& S_{v}=\text { activity per unit volume, } \\
& (\gamma / \mathrm{sec}) / \mathrm{cm}^{3} \\
& r=r_{a}+r_{s}, \mathrm{~cm} \\
& (\mu / \rho)_{a},(\mu / \rho)_{s}=\text { air and soil mass attenuation } \\
& \text { coefficients, } \mathrm{cm}^{2} / \mathrm{g} \\
& \rho_{a}, \rho_{s}=\text { air and soil density, } \mathrm{g} / \mathrm{cm}^{3}
\end{aligned}
$$

This expression assumes a source distribution which varies only with depth. A uniform distribution in the horizonal plane is assumed, which leads to results expressed in terms of an averaged value over the field of view of the detector.

The detector response to a given flux, $\phi$, of gamma rays of energy, $E$, incident at an angle, $\theta$, can be given in terms of an effective detector area, $A$, defined by

$$
A=\frac{N_{p}}{\phi}
$$

where $N_{p}$ is the net photopeak count rate, normally given in units of counts per second. The effective area, in general, varies as a function of the gamma ray angle of incidence and is usually written as

$$
A=A_{o} R(\theta)
$$

where

$$
\begin{aligned}
A_{0}= & \text { detector photopeak count rate for a unit flux } \\
\text { incident perpendicular to the detector face, } & \\
& (\mathrm{cps}) /\left[\gamma /\left(\mathrm{cm}^{2}-\mathrm{sec}\right)\right]
\end{aligned}
$$

$$
\begin{aligned}
R(\theta)= & \text { ratio of the detector response at an angle, } \theta, \\
& \text { to that at } \theta=0^{\circ}
\end{aligned}
$$

Combining Equations 11 and 12 with Equation 10 leads to an expression which relates the measured photopeak count rate to source activity in the soil. This is given by

$$
N_{p}=\int_{0}^{\infty} \int_{0}^{\infty} \frac{S_{\nu} A_{o} R(\theta)}{4 \pi r^{2}} \times
$$

$$
e^{\left[-(\mu / \rho) a \rho_{a} r_{a}\right]_{e}\left[-(\mu / \rho)_{s} \rho_{s} r_{s}\right]} 2 \pi x d x d z
$$

In order to evaluate Equation 13, it is necessary to make some assumptions on the source distribution depth. Three primary types of source distributions are normally encountered in environmental measurements. Naturally-occurring background radiation is usually represented by a uniform volume distribution. Relatively fresh fallout activity is normally represented by a uniform surface distribution. Fallout activity which has aged into the soil over a period of time is most often represented by an exponential distribution of the form

$$
S_{v}=S_{v}^{o} e^{-a z}
$$

where

$$
\begin{aligned}
S_{v}^{o}= & \text { activity per unit volume at the surface, } \\
& (\gamma / \mathrm{sec}) / \mathrm{cm}^{3} \\
\alpha= & \text { reciprocal of the relaxation depth, } \mathrm{cm}^{-1} \\
z= & \text { source distribution depth in the soil, } \mathrm{cm}
\end{aligned}
$$

This implies that the representative volume of soil at a depth of $1 / \alpha$ is assumed to contain approximately $63 \%$ of the source's total activity. At a relaxation depth of $2 / \alpha$ and $3 / \alpha$, respectively, the representative volume of soil is assumed to contain approximately $86 \%$ and $95 \%$ of the total activity.

For this exponential soil depth distribution, Equation 13 becomes 


$$
N_{p}=\frac{S_{v}^{o} A_{o}}{2} \int_{0}^{\pi / 2} \frac{R(\theta) \tan (\theta) e^{\left[-(\mu / \rho)_{a} \rho_{a} h \sec (\theta)\right]}}{a+(\mu / \rho)_{s} \rho_{s} \sec (\theta)} d \theta
$$

This expression relates the measured photopeak count rate, $N_{p}$, to the activity per unit volume at the surface. The detector parameters, $A_{o}$ and $R(\theta)$, are normally obtained empirically for a given system using standard calibration sources. Mass attenuation coefficients for air and typical soils can be found in standard reference tables. An average soil density of $1.5 \mathrm{~g} / \mathrm{cm}^{3}$ and air density of $0.001205 \mathrm{~g} / \mathrm{cm}^{2}$ at $20^{\circ} \mathrm{C}$ are normally assumed unless actual measured values are available. The detector height, $h$, can be measured in most cases.

In general, it is more useful to relate the photopeaknet count rate data to an average concentration within a given depth rather than a surface concentration as given in Equation 15. The average concentration in the top $z \mathrm{~cm}$ of soil, $S_{v}(z)$, for a source distributed exponentially with depth is given by

$$
S_{v}(z)=\frac{1}{z} \int_{0}^{z} S_{v}^{o} e^{-\alpha z} d z=\frac{S_{\nu}^{o}}{\alpha z}\left(1-e^{-\alpha z}\right)
$$

Another result often required is the total activity per unit area. This is given by

$$
S_{A}=\int_{0}^{\infty} S_{v}^{o} e^{-a z} d z=\frac{S_{v}^{o}}{a}
$$

The conversion factors derived for all three source distribution types relate a measured photopeak net count rate, expressed in units of counts per second (cps), to source activity expressed in units of gamma rays per second $(\gamma / \mathrm{sec})$ per unit area or unit volume. For a specific isotope, the source activity is normally changed to units of curies or becquerels. The average activity per unit volume can also be converted to average activity per unit mass by dividing by the soil density.
In the above model, the values for $\alpha$ and $z$, which are normally measured in the field, are usually poorly known and are highly dependent upon the actual soil conditions and isotopes present. Also, artificial soil disturbance (farming, construction, etc.) will affect the value of these parameters.

\subsection{RESULTS}

\subsection{Terrestrial Gamma Exposure Rate Contour}

The terrestrial gamma exposure rates inferred from the aerial data are shown in the form of a contour map superimposed on the 1995 aerial photograph of the survey area in Figure 6 . The levels shown include an estimated cosmic ray contribution of $4.4 \mu \mathrm{R} / \mathrm{h}$ at one meter above the ground.

Over most of the survey area, the inferred exposure rates represent normal fluctuations in the natural background radiation and range from approximately 9 to $17 \mu \mathrm{R} / \mathrm{h}$. On the base, these levels typically ranged from 11 to $15 \mu \mathrm{R} / \mathrm{h}$ over the populated and flight line areas, and 13 to $17 \mu \mathrm{R} / \mathrm{h}$ over the AMARC. Outside of the base boundaries, the levels typically ranged from less than 9 to $11 \mu \mathrm{R} / \mathrm{h}$ over the Detention Basin and Lakeside Park areas, 11 to $15 \mu \mathrm{R} / \mathrm{h}$ over the city's residential and industrial areas, and 9 to $17 \mu \mathrm{R} / \mathrm{h}$ over the unpopulated/farm areas. The detected exposure rates are well within the range of 1 to $20 \mu \mathrm{R} / \mathrm{h}$ found throughout the contiguous United States, Hawaii, and Alaska. ${ }^{8}$ A gamma energy spectrum of the natural background radiation in the survey area is shown in Figure 7.

Exposure rate levels ranging from 13 to $20 \mu \mathrm{R} / \mathrm{h}$ were detected over the Southern Pacific railroad yard and 15 to $17 \mu \mathrm{R} / \mathrm{h}$ over portions of the railroad line track bed areas residing in the survey area. Examination of the gamma energy spectra and the excess ${ }^{214} \mathrm{Bi}$ contour map revealed the presence of enhanced natural background radiation, primarily excess ${ }^{214} \mathrm{Bi}$ (natural uranium and its progeny). A gamma energy spectrum of the excess ${ }^{214} \mathrm{Bi}$ activity over the Southern Pacific railroad yard is shown in Figure 8.

\subsection{Detected Anomalies}

The abundance of ${ }^{214} \mathrm{Bi}$ in the environment can be separated into two categories: 1) where the ratio of ${ }^{214} \mathrm{Bi}$ to thorium and its progeny is typical of the natural background isotope mix, and 2) where this ratio is in 


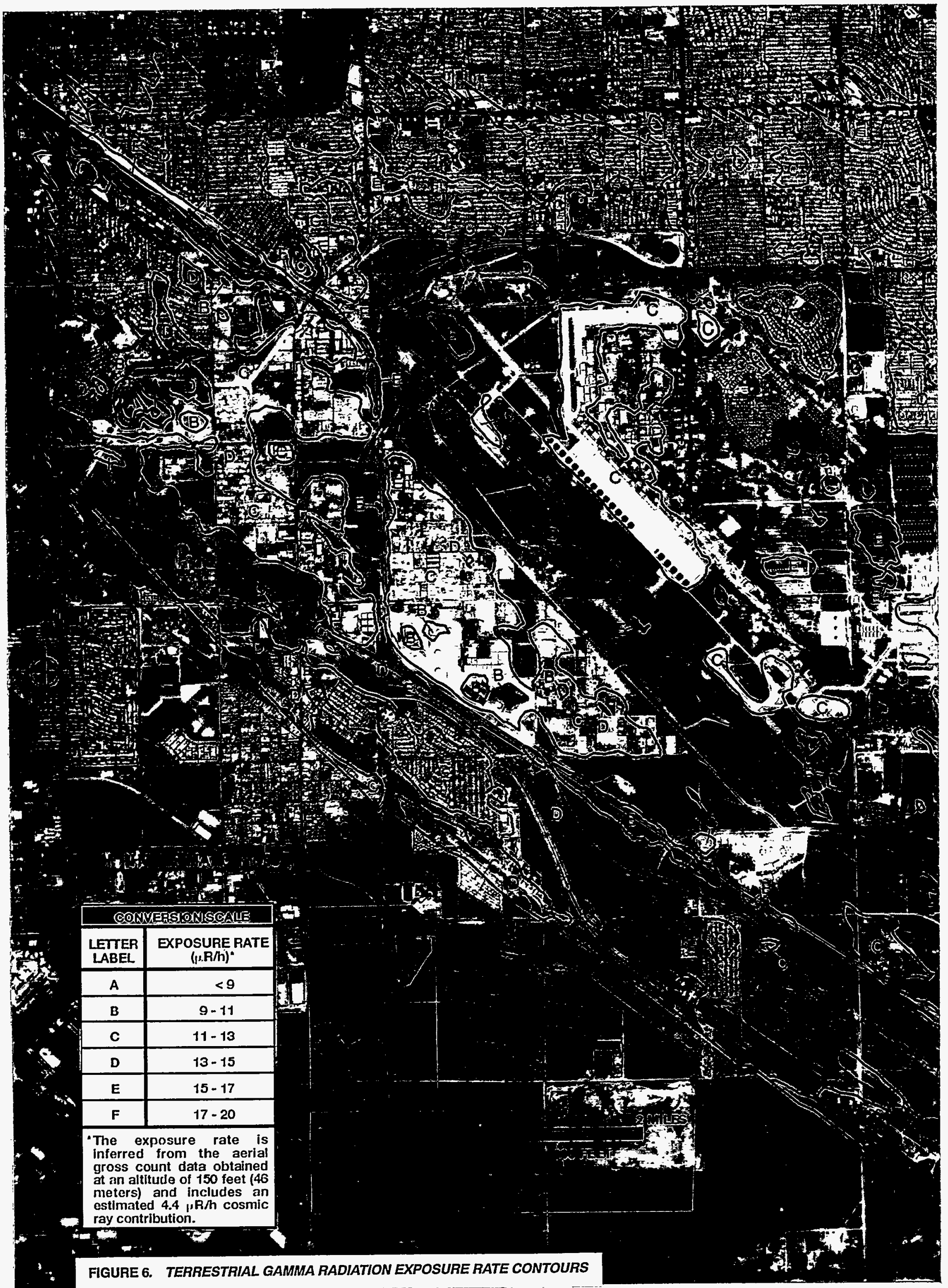




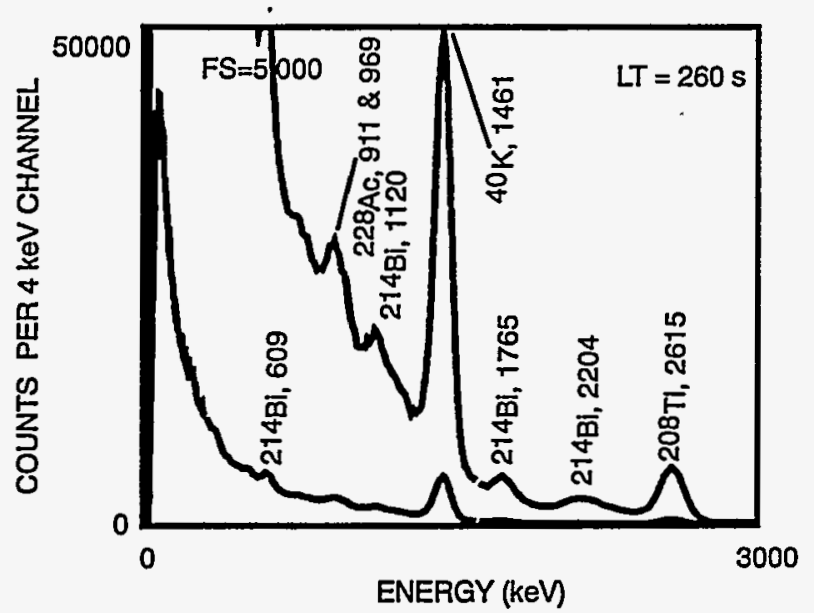

FIGURE 7. BACKGROUND GAMMA ENERGY SPECTRUM

excess of the expected ratio mix. Generally, such a deviation from the norm would be indicative of an increase in the abundance of ${ }^{214} \mathrm{Bi}$. An increase in this abundance may be natural as with certain geological features or it may be elevated by human introduction or technological enhancement of the natural ${ }^{214} \mathrm{Bi}$ or uranium. The ${ }^{214} \mathrm{Bi}$ algorithm, Equation 5 , was used to search the aerial data for locations of ${ }^{214} \mathrm{Bi}$ activity in excess of the expected natural isotopic ratios. The resulting isoradiation contour map is shown in Figure 9. The principal regions of interest are along the Southern Pacific railroad lines, residing both inside and outside the base, and the railroad yard. The enhanced levels of the natural ${ }^{214} \mathrm{Bi}$ activity ranged from 1.2 to $2.7 \mathrm{pCi} / \mathrm{g}$ along the base rail line, 1.2 to 5.5 $\mathrm{pCi} / \mathrm{g}$ along the primary rail line outside the base, and 1.2 to $9.8 \mathrm{pCi} / \mathrm{g}$ over the railroad yard. The minimum detectable activity of the aerial system was $1.2 \mathrm{pCi} / \mathrm{g}$.

The MMGC algorithm, Equation 3, was used to search the aerial data for man-made emitters. No man-made anomalies, which include ${ }^{137} \mathrm{Cs}$ and $234 \mathrm{mPa}$, were detected by the aerial system. However, as discussed in Section 5.1.2, the only activity shown on the MMGC contour count rate plot resulted from the "false-positive" anomalies generated by the higher-than-normal concentrations of natural ${ }^{214} \mathrm{Bi}$. The locations of those anomalies are depicted in Figure 9. Hence, the MMGC contour map is not presented.

\subsection{Ground-Based Measurements}

Ground-based exposure rate and in situ HPGe spectrometer measurements were collected at a

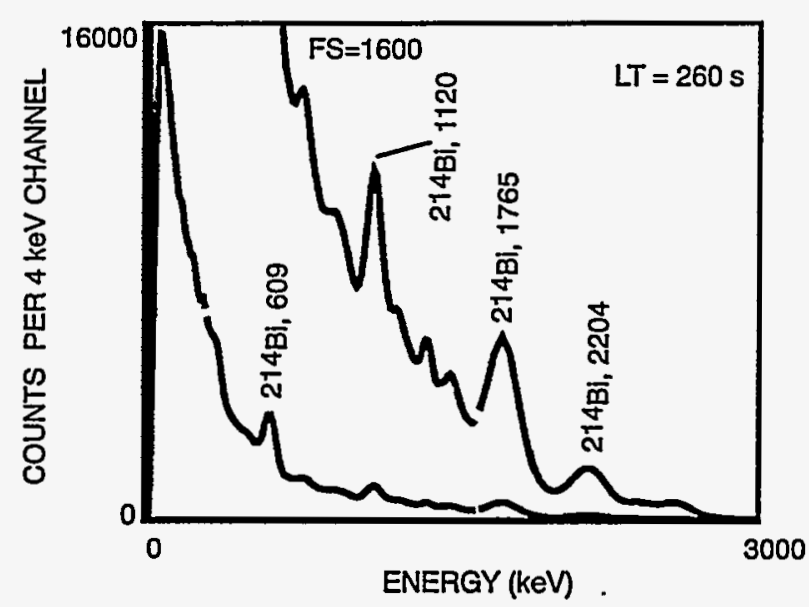

FIGURE 8. NET GAMMA ENERGY SPECTRUM OF THE ENHANCED NATURAL ${ }^{214 B i}$ ACTIVITY OVER THE SOUTHERN PACIFIC RAILROAD YARD.

height of one meter above ground at eight locations on the DMAFB during the aerial survey (see Figure 9).

The results of the in situ measurements, Table 4, are reported as HPGe-estimated soil concentrations in $\mathrm{pCi} / \mathrm{g}$ and are representative of the source activity averaged over the top $3 \mathrm{~cm}$ of soil. A relaxation depth $(1 / \alpha)$ of $10 \mathrm{~cm}$ was used for ${ }^{137} \mathrm{Cs}$. For the naturallyoccurring background radionuclides (uranium, thorium, and potassium), a uniform volume distribution was assumed. The relaxation depths cited were used in the derivation of the isotopic conversion factors and are representative values based on soil profile data collected at various sites throughout the United States.

Minute concentrations of ${ }^{137} \mathrm{Cs}$ were detected at six of the eight locations and ranged between 0.1 and 0.3 $\mathrm{pCi} / \mathrm{g}$. These values were below the minimum detectable activity of the aerial system and were consistent with those values expected from the worldwide residual fallout associated with the atmospheric nuclear weapons tests that had occurred in the 1950s and early $1960 \mathrm{~s}$. No $234 \mathrm{mPa}$ was detected at any of the in situ measurement locations. An HPGe gamma energy spectrum of one of these locations is shown in Figure 10.

The inferred in situ exposure rates, Table 3 (Section 5.2), were computed from the primary isotopic concentrations in the soil in accordance with the works of Beck, et al. ${ }^{5}$ The inferred aerial and in situ exposure rates include an estimated cosmic ray contribution of $4.4 \mu \mathrm{R} / \mathrm{h}$. 


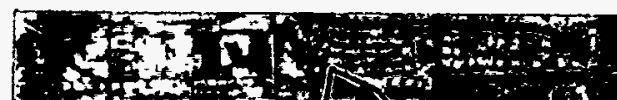

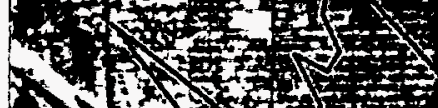
$b_{1}+2+2$

(1)

$15 x$

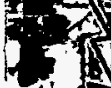

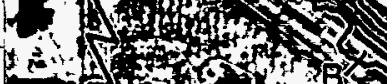

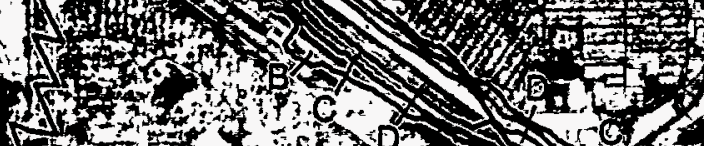

T. 7 T

Ten

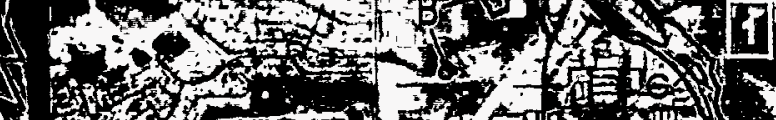

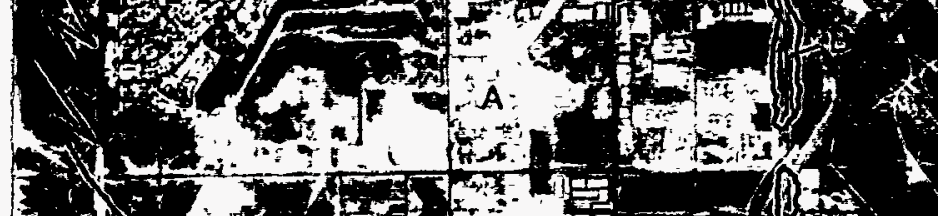

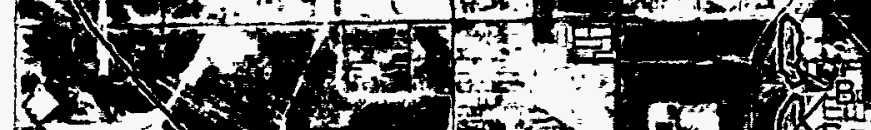

38 (3)

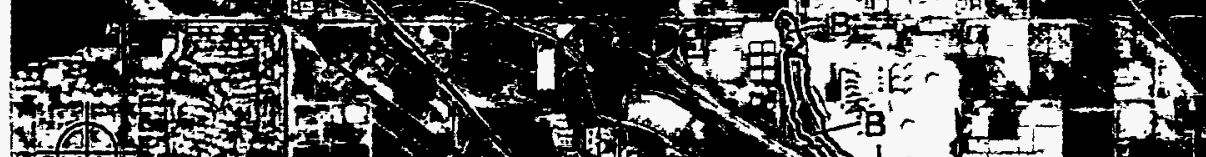

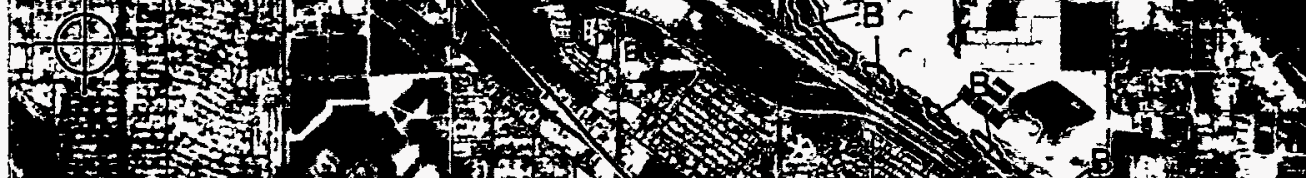

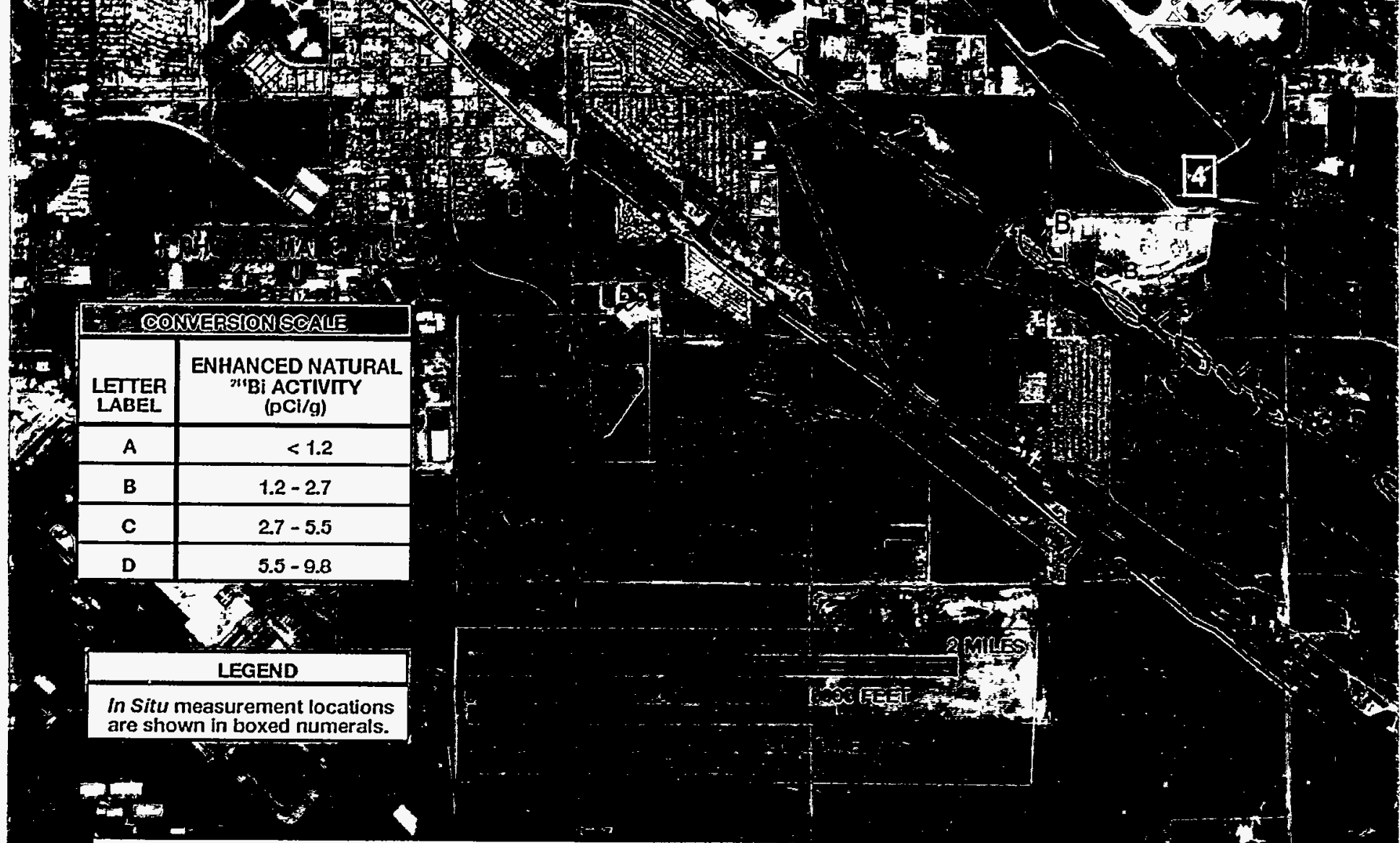




\begin{tabular}{|c|c|c|c|c|c|c|}
\hline \multirow[b]{2}{*}{ Site } & \multicolumn{2}{|c|}{ GPS Coordinates } & \multirow{2}{*}{${ }^{238 U}$} & \multirow[b]{2}{*}{$\begin{array}{c}\text { 232Th } \\
\text { (pci/g) }\end{array}$} & \multirow[b]{2}{*}{$\begin{array}{l}{ }^{137} \mathrm{Cs} \\
(\mathrm{pCi} / \mathrm{g})\end{array}$} & \multirow[b]{2}{*}{$\begin{array}{c}{ }^{40} \mathrm{~K} \\
(\mathrm{pCi} / \mathrm{g})\end{array}$} \\
\hline & $\begin{array}{l}\text { Latitude } \\
\text { (N) }\end{array}$ & $\begin{array}{l}\text { Longitude } \\
\text { (W) }\end{array}$ & & & & \\
\hline 1 & $32^{\circ} 11^{\prime} 16.8^{\prime \prime}$ & $110^{\circ} 54^{\prime} 21.8^{\prime \prime}$ & $0.7(0.1)$ & $1.0(0.1)$ & $0.24(0.03)$ & $26.8(0.3)$ \\
\hline 2 & $32^{\circ} 10^{\prime} 05.0^{\prime \prime}$ & $110^{\circ} 53^{\prime} 32.9^{\prime \prime}$ & $0.8(0.1)$ & $1.0(0.1)$ & MDA & $24.8(0.3)$ \\
\hline 3 & $32^{\circ} 11^{\prime} 03.8^{\prime \prime}$ & $110^{\circ} 52^{\prime} 36.5^{\prime \prime}$ & $0.7(0.1)$ & $1.2(0.1)$ & MDA & $23.1(0.3)$ \\
\hline 4 & $32^{\circ} 08^{\prime} 37.4^{\prime \prime}$ & $110^{\circ} 51^{\prime} 47.4^{\prime \prime}$ & $0.7(0.1)$ & $0.9(0.1)$ & $0.28(0.03)$ & $25.8(0.3)$ \\
\hline 5 & $32^{\circ} 10^{\prime} 16.9^{\prime \prime}$ & $110^{\circ} 50^{\prime} 51.4^{\prime \prime}$ & $0.8(0.1)$ & $1.0(0.1)$ & $0.15(0.04)$ & $26.2(0.4)$ \\
\hline 6 & $32^{\circ} 08^{\prime} 03.2^{\prime \prime}$ & $110^{\circ} 49^{\prime} 05.6^{\prime \prime}$ & $0.6(0.1)$ & $1.1(0.1)$ & $0.15(0.04)$ & $25.2(0.4)$ \\
\hline 7 & $32^{\circ} 07^{\prime} 34.8^{\prime \prime}$ & $110^{\circ} 47^{\prime} 55.0^{\prime \prime}$ & $0.6(0.1)$ & $1.0(0.1)$ & $0.27(0.03)$ & $25.2(0.3)$ \\
\hline$C P$ & $32^{\circ} 11^{\prime} 10.5^{\prime \prime}$ & $110^{\circ} 53^{\prime} 01.1^{\prime \prime}$ & $0.7(0.1)$ & $1.1(0.1)$ & $0.11(0.02)$ & $27.0(0.3)$ \\
\hline
\end{tabular}

a Measurement uncertainty (error) is enclosed in parentheses and represents one sigma counting error plus errors associated with system dead time and soil concentration conversion factor derivation.

bData acquired using a live-time counting interval of 900 seconds.

'Minimum Detectable Activity (MDA): ${ }^{137} \mathrm{Cs}=0.10 \mathrm{pCi} / \mathrm{g} .{ }^{238} \mathrm{U}=0.2 \mathrm{pCi} / \mathrm{g} .{ }^{232} \mathrm{Th}=0.2 \mathrm{pCi} / \mathrm{g} .{ }^{40} \mathrm{~K}=0.9 \mathrm{pCi} / \mathrm{g} .{ }^{234 \mathrm{mPa}} \mathrm{was}$ not detected (MDA $=6.7 \mathrm{pCi} / \mathrm{g}$ ).

${ }^{d}$ Auniform volume distribution was assumed for ${ }^{238} \mathrm{U},{ }^{232} \mathrm{Th}$, and ${ }^{40} \mathrm{~K}$. An exponential distribution with $\alpha$ equal to $0.1 \mathrm{~cm}^{-1}$ was assumed for ${ }^{137}$ Cs.

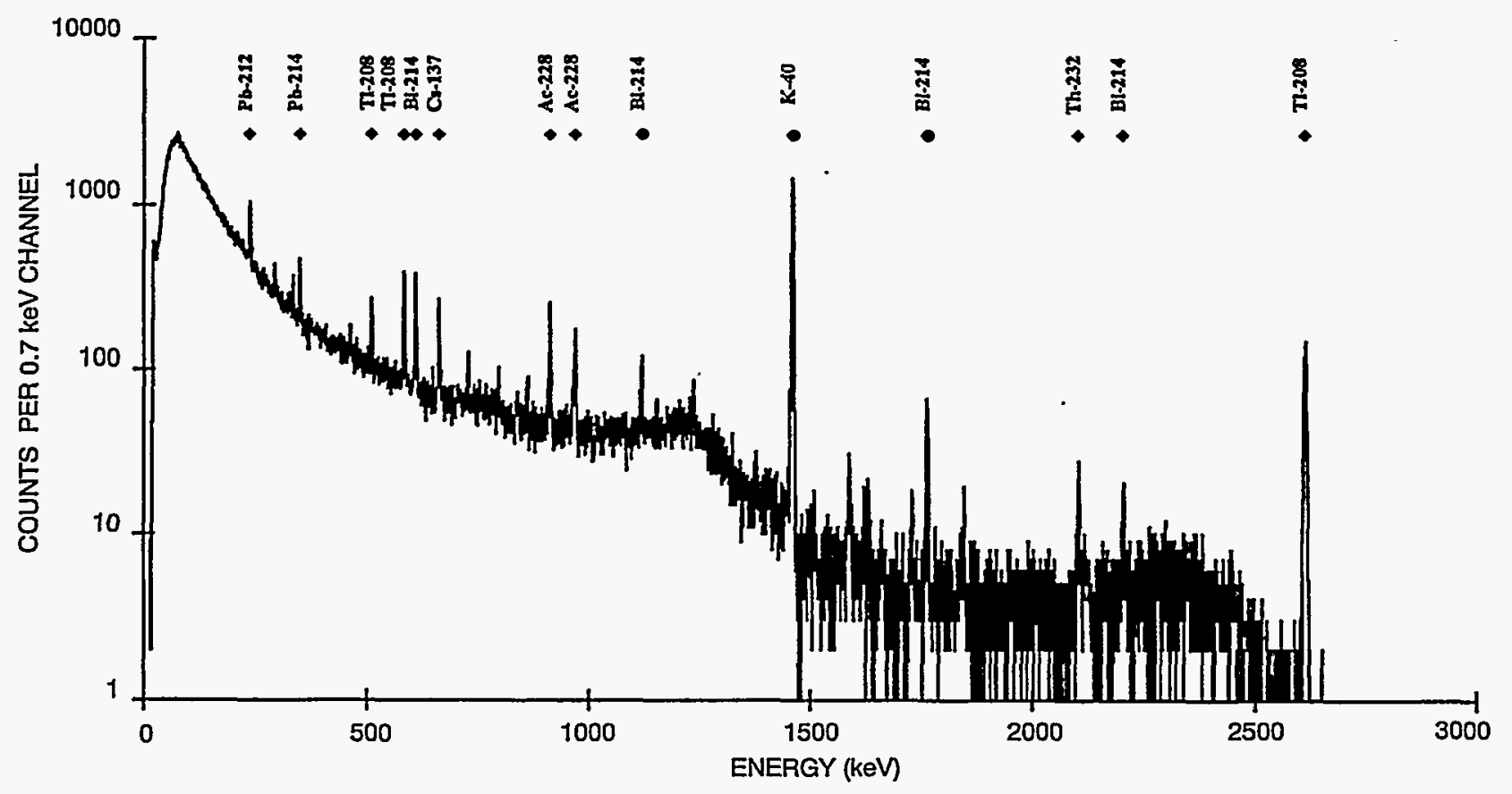

FIGURE 10. HPGe GAMMA ENERGY SPECTRUM OF THE DMAFB RIFLE RANGE AREA (SITE 7) 
At all locations, the inferred aerial-estimated exposure rates are in good agreement with both the ion chamber and the inferred in situ-estimated data. Any small disagreements between the aerial and ground data can be attributed to the following differences:

1. The aerial data are not taken at exactly the same place as the ground data. This could result in a comparison between two geographically different areas.

2. Differences arise between the fields of view of the detector systems. Each aerial data point covers an area several thousand times larger than data from a measurement made at one meter above the ground. Hence, the aerial system may detect radiation sources not seen by the in situ system. Conversely, the aerial system may see a large region of low activity with one small "hot" area, whereas the in situ system may be situated on the "hot" area.

\subsection{CONCLUSION}

An aerial radiological survey of the Davis-Monthan Air Force Base and surrounding area was conducted from March 1 to 13,1995 . The aerial survey was flown at an altitude of 150 feet (46 meters) AGL. No detectable man-made radionuclides were observed. However, elevated levels of natural uranium activity, ${ }^{214} \mathrm{Bi}$, were detected over the Southern Pacific railroad yard and along the railroad track bed areas residing inside and outside the base boundaries. The typical external exposure levels emanating from within the survey area ranged from 9 to $20 \mu \mathrm{R} / \mathrm{h}$ at one meter $A G L$, which is well within the range found throughout the contiguous United States, Hawaii, and Alaska.

The presence of ${ }^{137} \mathrm{Cs}$ was detected on the base using the in situ measuring system. The quantities detected ranged from 0.1 to $0.3 \mathrm{pCi} / \mathrm{g}$, which is well within the range expected from the world wide residual fallout associated with the early atmospheric nuclear weapons tests. 


\section{APPENDIX A}

\section{SURVEY PARAMETERS}

Survey Site:

Davis-Monthan Air Force Base

Tucson, Arizona

Survey Coverage: $\quad 51 \mathrm{mi}^{2}\left(132 \mathrm{~km}^{2}\right)$

Survey Dates: March 1 to 13,1995

Survey Altitude: $\quad 150 \mathrm{ft}(46 \mathrm{~m})$

Average Ground Speed: $\quad 70$ knots $(36 \mathrm{~m} / \mathrm{s})$

Line Spacing: $\quad 250 \mathrm{ft}(76 \mathrm{~m})$

Number of Survey Lines: 146

Navigation System: Real-Time Differential Global Positioning System

Line Direction: Southeast-Northwest

Detector Configuration: $\quad$ Eight $4-\times 4-\times 16$-in Nal (TI) detectors Two 2- $\times 4-\times 4$-in Nal (TI) detectors

Acquisition System: REDAR IV

Aircraft:

MBB BO-105 Helicopter: Tail \#N70EG

Project Scientist:

D. Colton

Data Analyst:

W. Vincuilla

Aerial Data Processing:

1. Total Terrestrial Exposure Rate (Gross Count)

Energy Window: $38-3,026 \mathrm{keV}$

Conversion Factor: $1,114 \mathrm{cps}$ per $\mu \mathrm{R} / \mathrm{h}$

Cosmic Ray Contribution: $4.4 \mu \mathrm{R} / \mathrm{h}$

Air Attenuation Coefficient: $0.001757 \mathrm{ft}^{-1}\left(0.00576 \mathrm{~m}^{-1}\right)$

2. Man-Made Gross Count Rate (MMGC)

Source Energy Window: $38-1,394 \mathrm{keV}$

Background Energy Window: $1,394-3,026 \mathrm{keV}$

3. Bismuth-214 Count Rate $\left({ }^{214} \mathrm{Bi}\right.$, characteristic of natural uranium and its progeny)

Source Energy Window: 1,596-1,872 keV

Background Energy Window: 2,376-2,772 keV

Conversion Factor: $25.6 \mathrm{cps}$ per $\mathrm{pCi} / \mathrm{g}$

Uniform Distribution ( $\alpha$ ): $1.0 \mathrm{E}-06 \mathrm{~cm}^{-1}$

Soil Sample Depth (z): $3.0 \mathrm{~cm}$ 


\section{APPENDIX B}

\section{IN SITU MEASUREMENT PARAMETERS}

Survey Dates: $\quad$ March 8 to 10,1995

Number of Locations: $\quad 8$

Detector System: $\quad$ ORTEC HPGe N-type coaxial detector (S/N 34-TN20879)

Acquisition System: Davidson MCA Analyzer (S/N 5856)

Exposure Rate Monitor: Reuter-Stokes Pressurized lon Chamber

In Situ Data Processing:

1. Cesium-137 Count Rate

Source Energy Window: $653-671 \mathrm{keV}$

Conversion Factor: $2.9 \mathrm{cps}$ per $\mathrm{pCi} / \mathrm{g}$

Exponential Distribution $(\alpha): 0.1 \mathrm{~cm}^{-1}$

Soil Sample Depth (z): $3 \mathrm{~cm}$

2. Naturally-Occurring Isotope Count Rate

Conversion Factors:

Uniform Distribution ( $\alpha$ ): $1.0 \mathrm{E}-06 \mathrm{~cm}^{-1}$

Soil Sample Depth (z): $3 \mathrm{~cm}$

\begin{tabular}{lccc} 
Isotope & $\begin{array}{c}\text { Source Energy } \\
\text { Window }\end{array}$ & Conversion Factor & $\begin{array}{c}\text { Decay } \\
\text { Chain }\end{array}$ \\
\hline Potassium-40 & $1,450-1,470 \mathrm{keV}$ & $0.38 \mathrm{cps} \mathrm{per} \mathrm{pCi/g}$ & ${ }^{40} \mathrm{~K}$ \\
Bismuth-214 & $1,757-1,773 \mathrm{keV}$ & $0.53 \mathrm{cps} \mathrm{per} \mathrm{pCi/g}$ & ${ }^{238 \mathrm{U}}$ \\
Actinium-228 & $889-920 \mathrm{keV}$ & $1.10 \mathrm{cps} \mathrm{per} \mathrm{pCi/g}$ & ${ }^{232} \mathrm{Th}$
\end{tabular}




\section{REFERENCES}

1. Oden, K., Remedial Project Manager, DMAFB Environmental Restoration Project, Private Commuinication. March 1995.

2. Davis Monthan Air Force Base 1995. Benchmark Publications Inc., Escondido, California, 1994.

3. Boyns, P.K. The Aerial Radiological Measuring System (ARMS): Systems, Procedures and Sensitivity (1976), Report No. EGG-1183-1691. EG\&G, Las Vegas, Nevada, 1976.

4. Mohr, R.A. Ground Tiuth Measurements at the Calvert County, Maryland Test Line, Report No. EGG-10282-2066. EG\&G/EM, Santa Barbara, California, 1985.

5. Beck, H.L., J. DeCampo, and C. Gogolak. In Situ Ge(Li) and NaI(Tl) Gamma Ray Spectrometry, Report No. HASL-258, TID-4500. U.S. AEC Health and Safety Laboratory, New York, New York, 1972.

6. Knoll, G.F. Radiation Detection and Measurement, Second Edition. J. Wiley \& Sons, New York, New York, 1989, pp 120-128.

7. Reiman, R.T. "In Situ Gamma Analysis System," Proceedings of a Symposium on Remote Sensing Technology in Support of the United States Department of Energy, February 23-25, 1983, Las Vegas, Nevada, Report No. EGG-10282-1057. EG\&G/EM, Las Vegas, Nevada, 1985, Section 28, pp 1-24.

8. Lindeken, C.L., K.R. Peterson, D.E. Jones, and R.E. McMillen. "Geographical Variations in Environmental Radiation Background in the United States," Proceedings of the Second International Symposium on the Natural Radiation Environment, August 7-11, 1972, Houston, Texas. National Technical Information Service; Springfield, Virginia, 1972, pp 317-332. 